
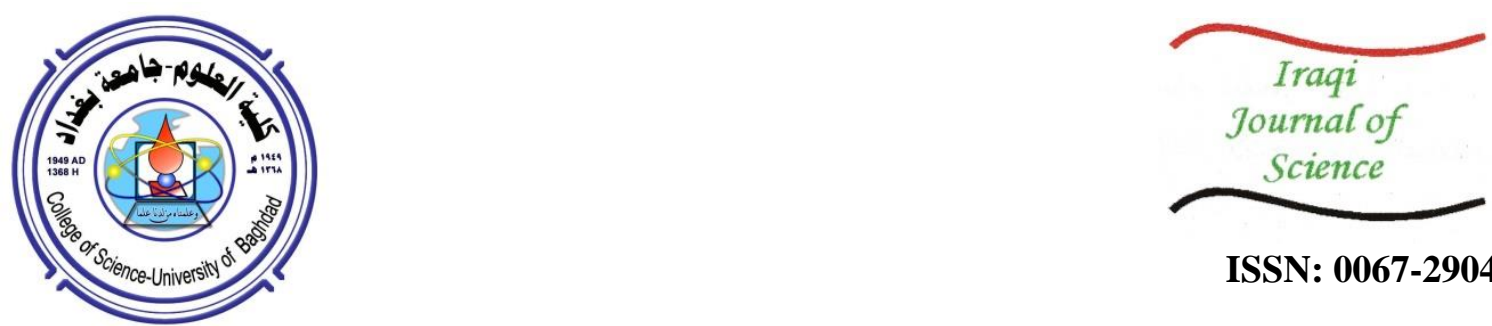

ISSN: 0067-2904

\title{
Subsurface Imaging of 2D Seismic Data Using Kirchhoff Time Migration Method, Central Iraq
}

\author{
Fadhil A. Obaid*1, Ali M. Al-Rahim ${ }^{1}$, Hassan Zaid Ali ${ }^{2}$ \\ ${ }^{1}$ Department of Geology, College of Science, University of Baghdad, Baghdad, Iraq \\ ${ }^{2}$ Seismic Data Processing Department, Oil Exploration Company, Ministry of Oil, Baghdad, Iraq
}

Received: $14 / 4 / 2020$

Accepted: 5/6/2020

\begin{abstract}
Kirchhoff Time Migration method was applied in pre-and post-Stack Time Migration for post-processing of images collected from Balad-Samarra (BS-92) survey line that is sited across Ajeel anticline oilfield. The results showed that Ajeel anticline structure was relocated at the correct position in the migrated stacked section. The two methods (Pre and Post) of migration processing showed enhanced subsurface images and increased horizontal resolution, which was clear after the broadening the syncline and narrowing or compressing the anticline. However, each of these methods was associated with migration noise. Thus, a Post-Stack process was applied using Dip-Removal (DDMED) and Band-Pass filters to eliminate the artifact noise. The time-frequency and signal to noise spectrum analyses as well as the ISO-velocity distribution analysis confirmed that the Pre-Stack Time Migration method outperformed the Post-Stack method as a result of structural complexity.
\end{abstract}

Keywords: Subsurface Imaging, Time Migration, Kirchhoff Method, BaladSamarra Area, Pre-Stack Time Migration, Post-Stack Time Migration, Bow-tie, Ajeel Anticline.

\section{تصوير تحت السطح بإستخدم طريقة كيركوف للتهجير الزمني للبيانات الزلزالية الأرضية ثنائية الأبعاد، وسط العراق
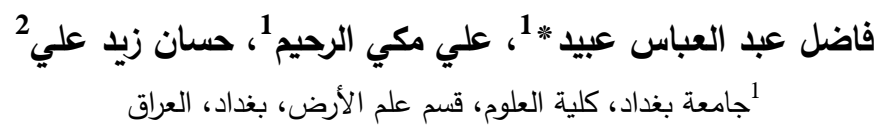

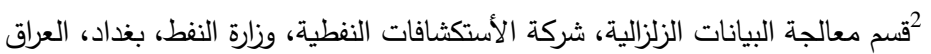

الخلاصه

تم تطبيق طريقة كيركوف للتهجير الزمني لمعالجة التصوير تحت السطحي لخط بلد - سامراء 92

الزلزالي لعملية قبل وبعد التضضيد والذي يقع عمودياً على ميل الطبقات لطية حقل عجيل النفطي. وقد أوضحت

النتائج إعادة موقع طية حقل عجيل الى موضعها الأصلي في المقطع الزلزالي المهجر . وقد أظهرت نتائج

طريقتي التهجيرالتحسن الواضح في الصورة التحت سطحية كذلك زيادة في الدقة الأفقية بعد توسع التراكيب

المقعرة وتضيق او انضغاط في التراكيب المحدبة ولكن لكل من هذه الطرق تإتي بضوضاء التهجير لذلك تم

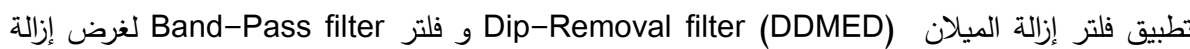

هذه الضوضاء. وكما أكتت تحاليل التردد - الزمن و الإشارة الى الضوضاء و تحليل السرع ان المقطع 


$$
\text { الدرجة تعقيد التركيب التحت سطحية ما قبل التنضيد هو افضل من المقطع الزلزالي المهجر لعملية ما بعد التضضيد نتيجة }
$$

\section{Introduction}

Seismic processing is a method that aims to produce a subsurface image that characterizes the subsurface geological structure from the acquired seismic data. Migration can be defined as the shift or repositioning of the dipping reflectors and seismic events to their accurate subsurface positions. Therefore, the migration transfers the dipping subsurface events in the up-dip path and collapses the diffractions. Hence, it enables the interpreters to demarcate, delineate, and explain the faults and other features, while recollecting the horizontal events in their original situations and increasing the special resolution, to produce a correct image of the subsurface [1,2]. Kirchhoff migration is one of the most common and simplest methods of migration used in the seismic processing. It depends on the assumption that the zero-offset section, composed of a single diffraction hyperbola that migrates as a full point migration, includes a summary of amplitudes along a hyperbolic curve [3, 4]. Kirchhoff migration is based on the secondary Huygens's principle which is states that "every point to which a wave reached becomes a source of a spherical wave". The summation of these secondary waves decides the arrangement of the wave at any successive time. In homogeneous media, the wavefront is a semi-circle when the velocity is constant for one trace that is being recorded $[3,5]$.

Consider a shot $(S)$ and receiver $(R)$ that are located near to each other. A reflector has a true dip angle $=(\alpha t)$ and is at a depth $(z)$ below the shot point. Seismic energy that returns to $(R)$ will reflect at $(A)$ where the seismic ray pathway is at $\left(90^{\circ}\right)$ to the reflector. However, in a seismic section, a reflection is designed as it was directly below the Shot-Receiver point, which in this case is $(B)$. Note that the line $(A-B)$ is the curve of the difference between the apparent and true reflector locations, centered at $(R S)$. The result is the reflector imaged by the seismic data with an apparent dip of $(\alpha s)$ that is less than the true dip ( $\alpha t)$ (Figure-1) [4].
A. From triangle $(\mathrm{A}-\mathrm{C}-\mathrm{RS})\left(\cos \alpha_{t}=\frac{p}{z}\right)$
B. From triangle $(\mathrm{O}-\mathrm{RS}-\mathrm{C})\left(\tan \alpha_{t}=\frac{z}{x}\right)$
C. From triangle $(0-\mathrm{RS}-\mathrm{B})\left(\tan \alpha_{s}=\frac{p}{x}\right)$
D. Rearranging these equations gives; $\left(\sin \alpha_{t}=\tan \alpha_{s}\right)$

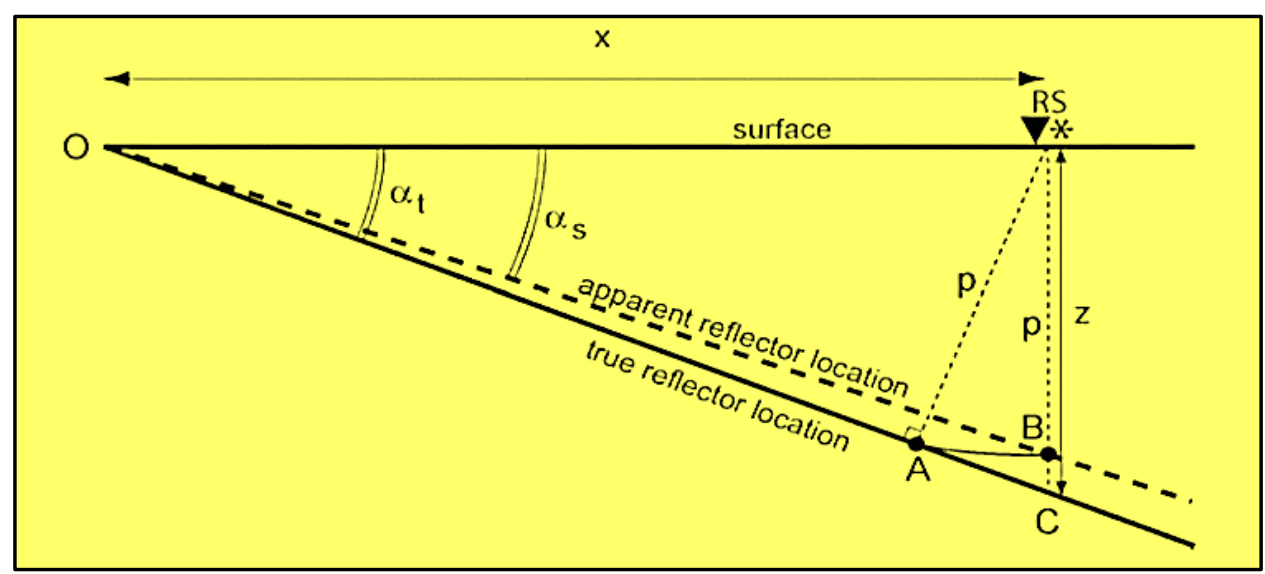

Figure 1- A sketch illustrating the dipping reflector layers imaged with an incorrect dip [4].

Practicality, the migrated velocity for time tomography at the time domain scatter point $(\mathrm{x}, \pi)$ is described numerically in definitions of accumulating the most diffracted energy from the correlating depth-domain dispersing level, sometimes referred to as the Double-Square-Root $(D S R)$ formula, which can be explained mathematically of CMP and offset domain as [6, 7]:

$$
T=\sqrt{\frac{t^{2}}{4}+\frac{\left(x_{\text {off surface }}-h\right)^{2}}{v^{2}}}+\sqrt{\frac{t^{2}}{4}+\frac{\left(x_{\text {off lateral surface }}+h\right)^{2}}{v^{2}}}
$$


where $\left(\boldsymbol{x}_{\text {off } \text { surface }}\right)$ represents a CMP surface location, $(h)$ represents the half source-receiver offset, and $\left(\boldsymbol{x}_{\text {off } f \text { lateral surface }}\right)$ represents the surface lateral distance between the CMP location and the scatter point $(x, \tau)$.

\section{Study Area and Data Available}

Balad-Samarra 92 seismic line (Figures- 2A and B) runs along the Ajeel oilfield. Ajeel oilfield is located at Salah Al-Din Governorate, 30 kilometers north of Tikrit city to the east of Tigris River

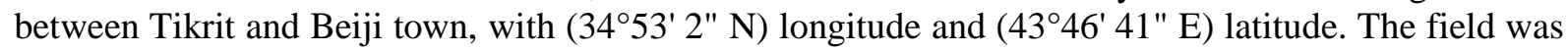
detected during a seismic survey in Hamrin-Ajeel area that was conducted in the period 1975-1979 [8, $9,10]$.

The tectonic framework placed Ajeel oilfield (Figure-2C) at the front platform plane of the Foredeep Basin of the Mesopotamian and at the low fold zone of Zagros fold belt. The structure of Ajeel comprises a double-plunging anticline, trending in the (NW-SE) direction, with approximately $150 \mathrm{~m}$ height and $10 \mathrm{~km}$ length on the top of the Quinta Formation [11, 12].

The information presented in the present study are related to the BS-92 seismic line, which was a part of a 2D seismic survey accomplished by the Iraqi Oil Exploration Company (IOEC) in 1983. The length of the seismic line is $31.8 \mathrm{~km}$ towards NE-SW, within the Dip-Strike. The field parameters indicated that the type of the source is dynamite, channels number is 96 , coverage is $2400 \%$, datum plane is $100 \mathrm{~m}$ ASL, type of spread is unbalance, sampling rate is $2 \mathrm{~ms}$, recording length is $6 \mathrm{sec}$, trace spacing is $50 \mathrm{~m}$, trace length is $115 \mathrm{~m}$, and the offset is $100 \mathrm{~m}$.

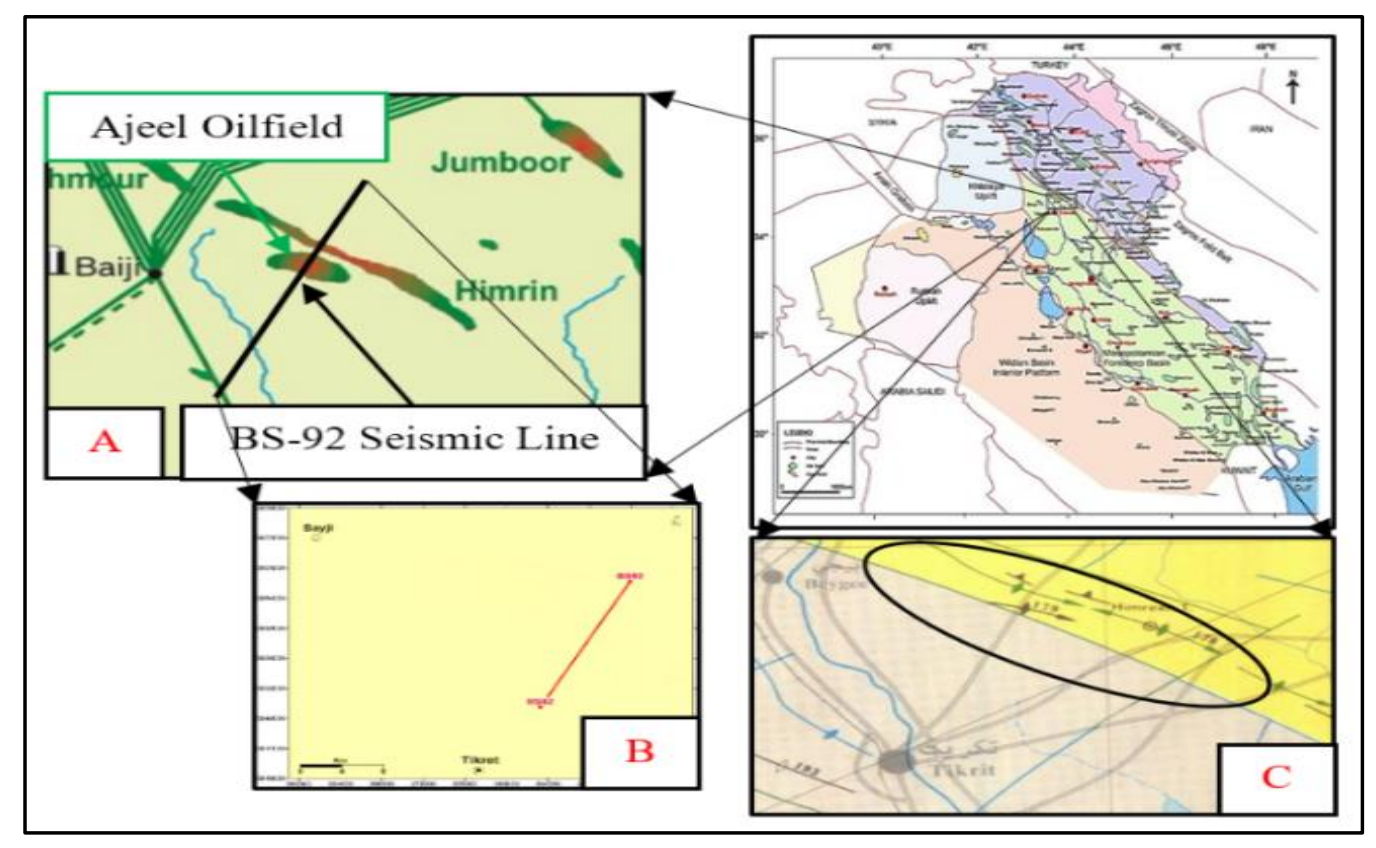

Figure 2- Location and tectonic maps of the BS-92 survey line in the study area [8, 12].

\section{Data processing and results}

The BS-92 survey line was reprocessed using the Geovation seismic processing system in the Iraqi Oil Exploration Company (IOEC) in 2019. Seismic processing is classified into four major stages: enhancement and formatting, spatial improvement, data enhancement, and finally postimaging. The sequencing takes several detailed steps to achieve the final post-processed image (Figure-3). In Kirchhoff time migration process, three parameters should be set and extended to all the seismic sections, that are migration aperture, migration velocity, and targeted range.

Before the migration process is applied, the seismic data must be passed in all the processing stages to become ready for the migration stage. Then, the residual static correction is applied to correct small inaccuracies in the near surface model and correct the residual two-way time to smoothing NMOcorrected of the seismic section with signal to noise ratio spectrum (SNR) (Figures- 4A and 4B). The synclines in the stacked section appears as "Bow-Tie" (Figure-4A). 


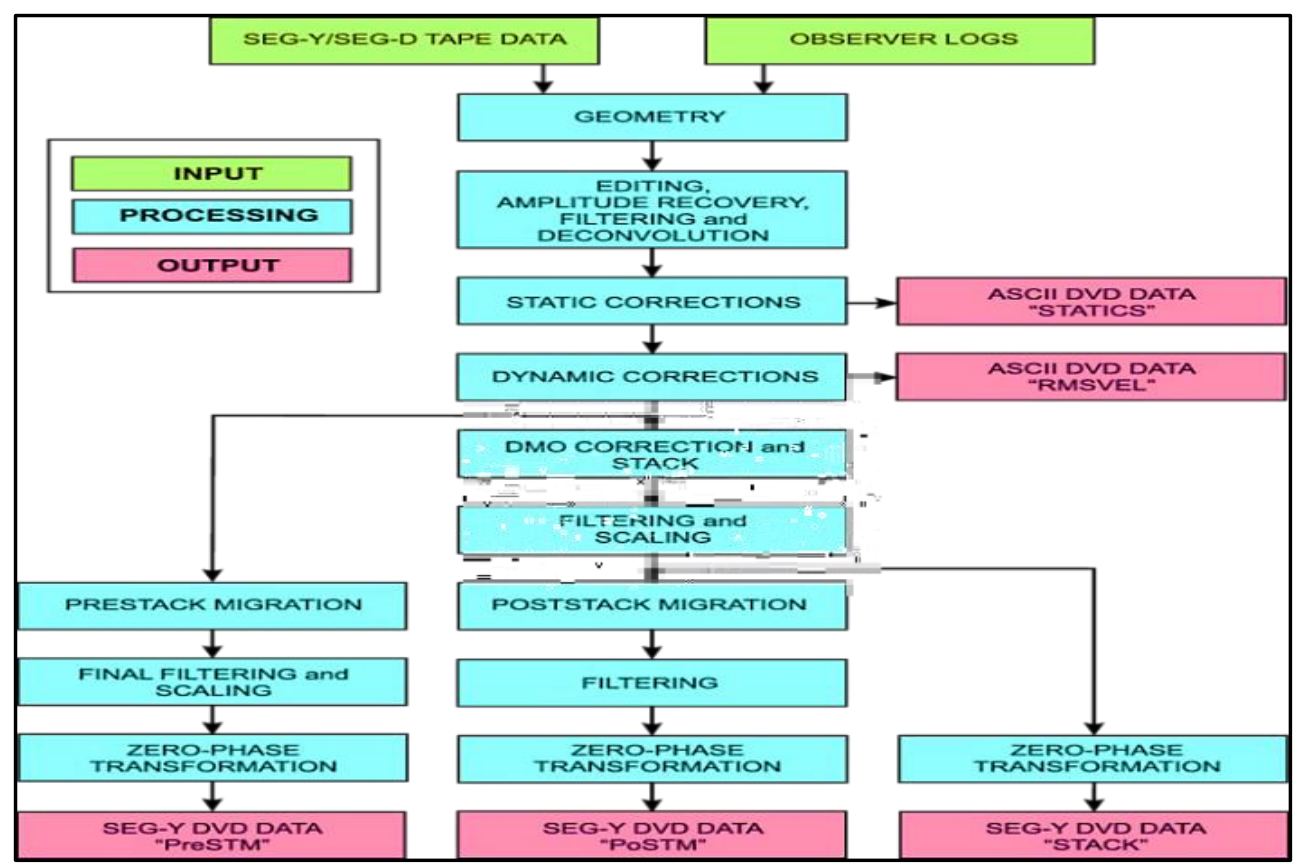

Figure 3- A sketch illustrating the sequence of seismic data processing [13].

The Bow-Tie syncline occurs as consequences of the existence of three separate reflections, where the curvature of the reflector exceeds that of the wavefront section on the seismic section which is not migrated $[1,13,14]$. Another reason behind the formation of the Bow-Tie in the stacked section is the fault- picking velocity in Kirchhoff migration produced by the usage of velocities lower than those considered to be as medium velocities [12,13]. In this study, Kirchhoff migration was applied, as described in the following steps.
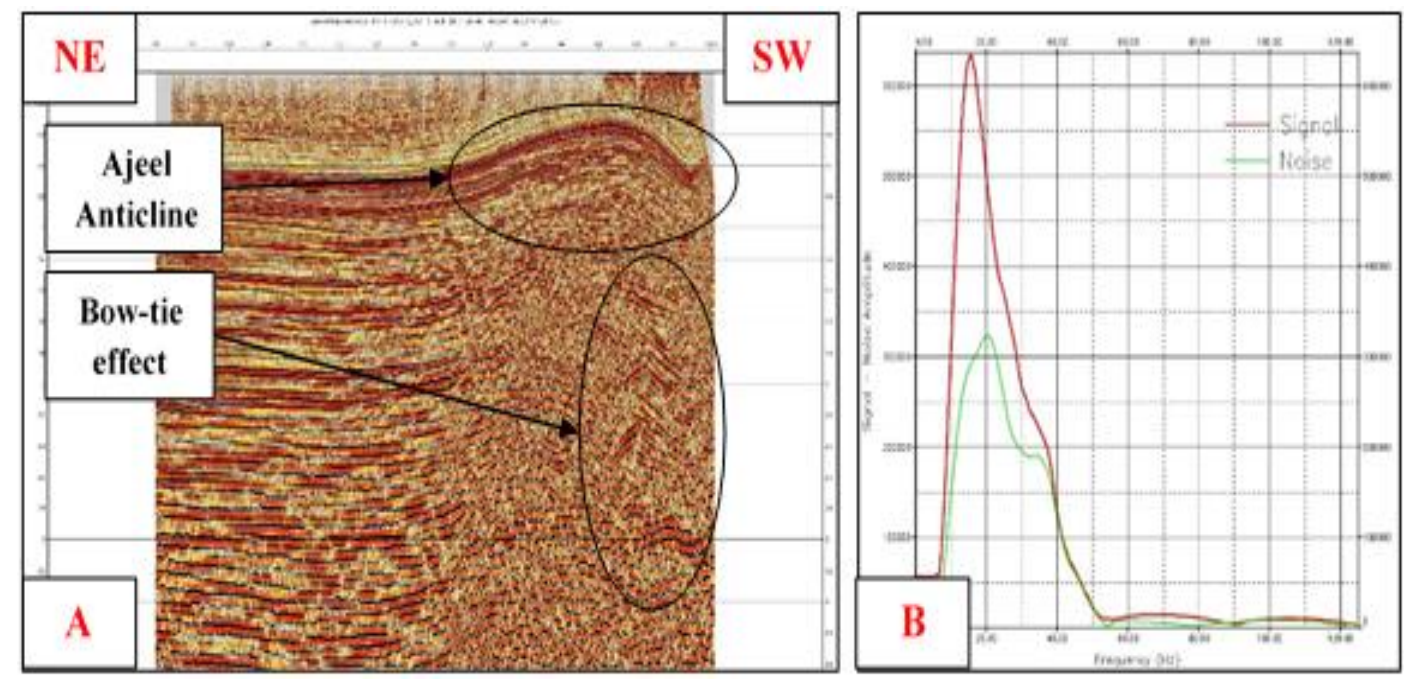

Figure 4- (A) Residual stacked seismic section of BS-92 seismic line showing Ajeel anticline and "Bow-tie" effect. (B) Signal to noise ratio amplitude.

\section{A. Post-Stack Time Migration (Post-STM)}

In Post-STM method, residual static correction can be still within the Post-STM parameters which is applied on the residual stack to obtain an accurate subsurface image in the progress of the work flow. Kirchhoff migration method was applied on stack data using the following selected values of several parameters: migration aperture of $2000 \mathrm{~m}$ (tested values ranged from 1000 to $3000 \mathrm{~m}$ ) with increment of $500 \mathrm{~m}$, dip angle cut of migration operator equal to $30^{\circ}$ (tested values ranged from 10 to $60^{\circ}$ ), and velocity smoothing and interpolation of $100 \%$ (tested values ranged from $90 \%$ to $110 \%$ ) with increment of $2 \%$. These selected values $\left(2000 \mathrm{~m}, 30^{\circ}\right.$, and $\left.100 \%\right)$ showed the best performance result for migration process. Post-STM method showed an improved image, and reduced the "Bow-tie" 
effect in the stack subsurface image, which is present in the residual stack (Figure-5A). The recovery of the desired signals, as shown by the SNR, confirms this result (Figure-5B).
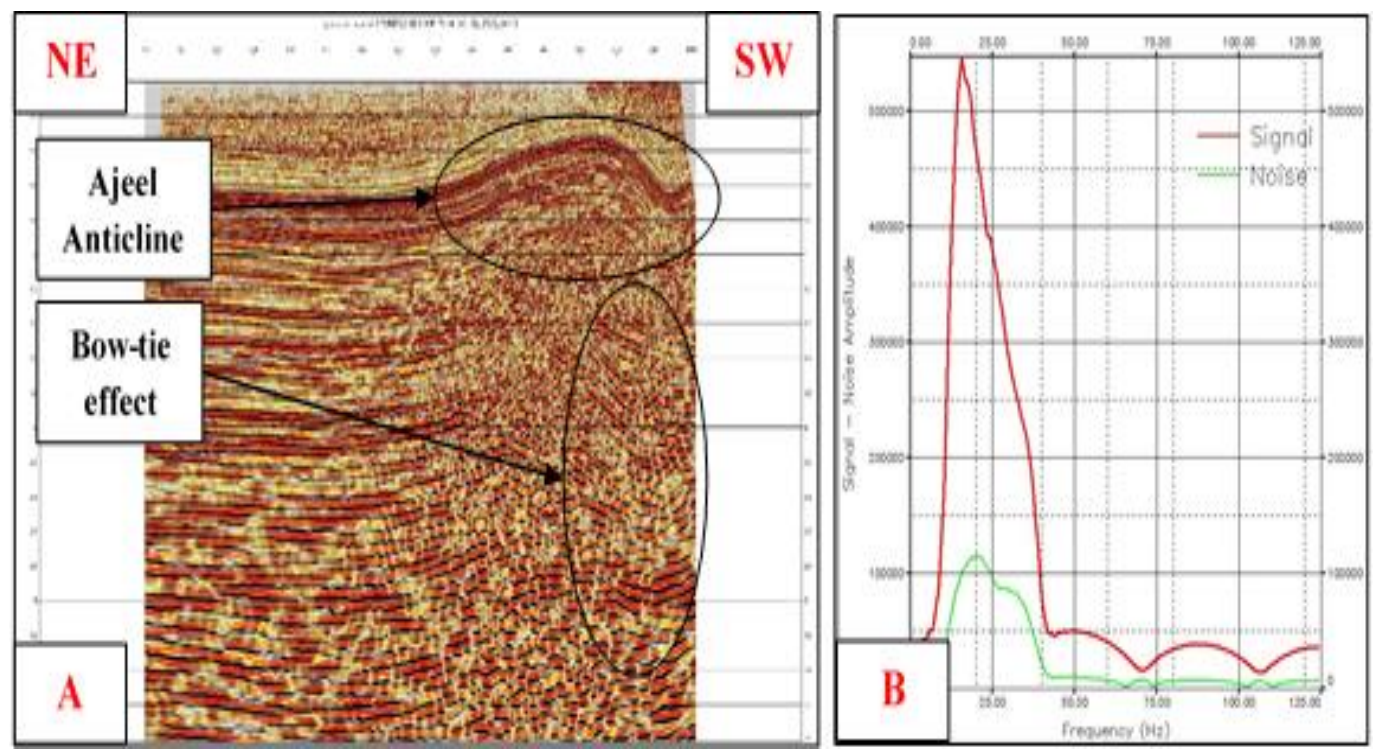

Figure 5- (A) Post-Stack Time Migration seismic section of BS-92 seismic line showing Ajeel anticline and "Bow-tie" effect. (B) Signal to Noise ratio amplitude.

The syncline structure in the seismic section, along the time of 1.3-3.2 sec. and in the CMP range of 2025-2513, became more broadened after applying the Post-Kirchhoff migration. Hence, Kirchhoff migration increased the accuracy of the subsurface structure and relocated the seismic data to their real position. The imaging process also resulted in side effects, e.g., dip noise, in the edges area caused by the migration operator's effect (Figure-6A). As known, dip-removal filter " $(f-k)$ Filter" could eliminate these side effects. The parameter of dip-removal filter fan dips (-8.8) (Figure-6B). For the quality control (QC) of the migration process, the Time-Frequency distribution slice (Figure-7) illustrates a clear difference between the image of residual stack (Figure-7A) and that of Post-Migrated stack section (Figure-7B). The Time-Frequency distribution slice shows successful performance of the migration process because it increased the SNR value, while the distribution of amplitude became more homogenous after applying the Post-STM.
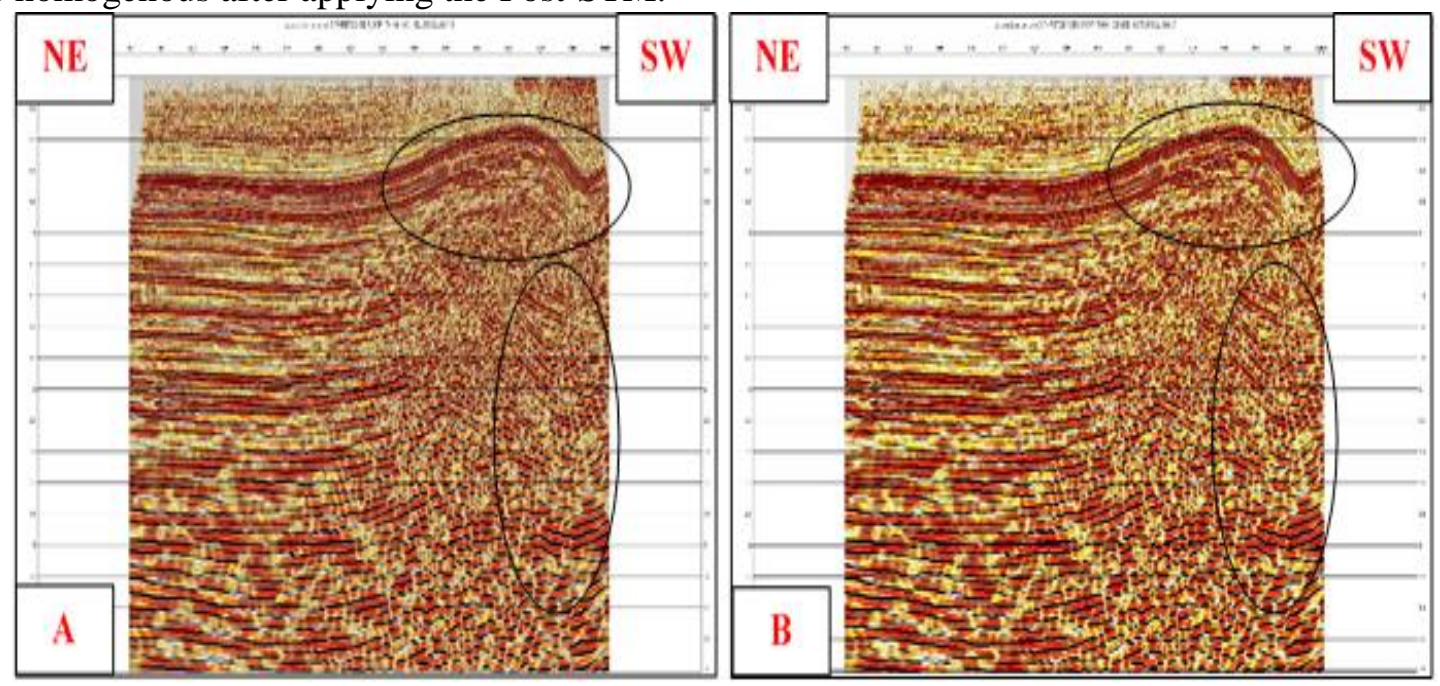

Figure 6- Stacked seismic section of BS-92 seismic line; (A) Post-Stack Time Migration without dipremoval filter. (B) Post-Stack Time Migration with dip-removal filter. 


\section{B. Pre-Stack Time Migration (Pre-STM)}

The same parameters utilized for the Post-Stack Time Migration of Kirchhoff method were used in the Pre-Migration stage. The seismic data were subdivided into classes of $100 \mathrm{~m}$ offset. After that, it was possible to apply the migration on the shot-points after removing all the unnecessary data, such as noise (Figure-8A).

Also, the steps of re-picking a new velocity and applying NMO were taken into consideration. The offset classes are a type of data sorting approaches that depends on the offset unit of the investigation. Ajeel area is subdivided into $100 \mathrm{~m}$ offset classes, as a single data processing approach with migration operations (Figure-8B).
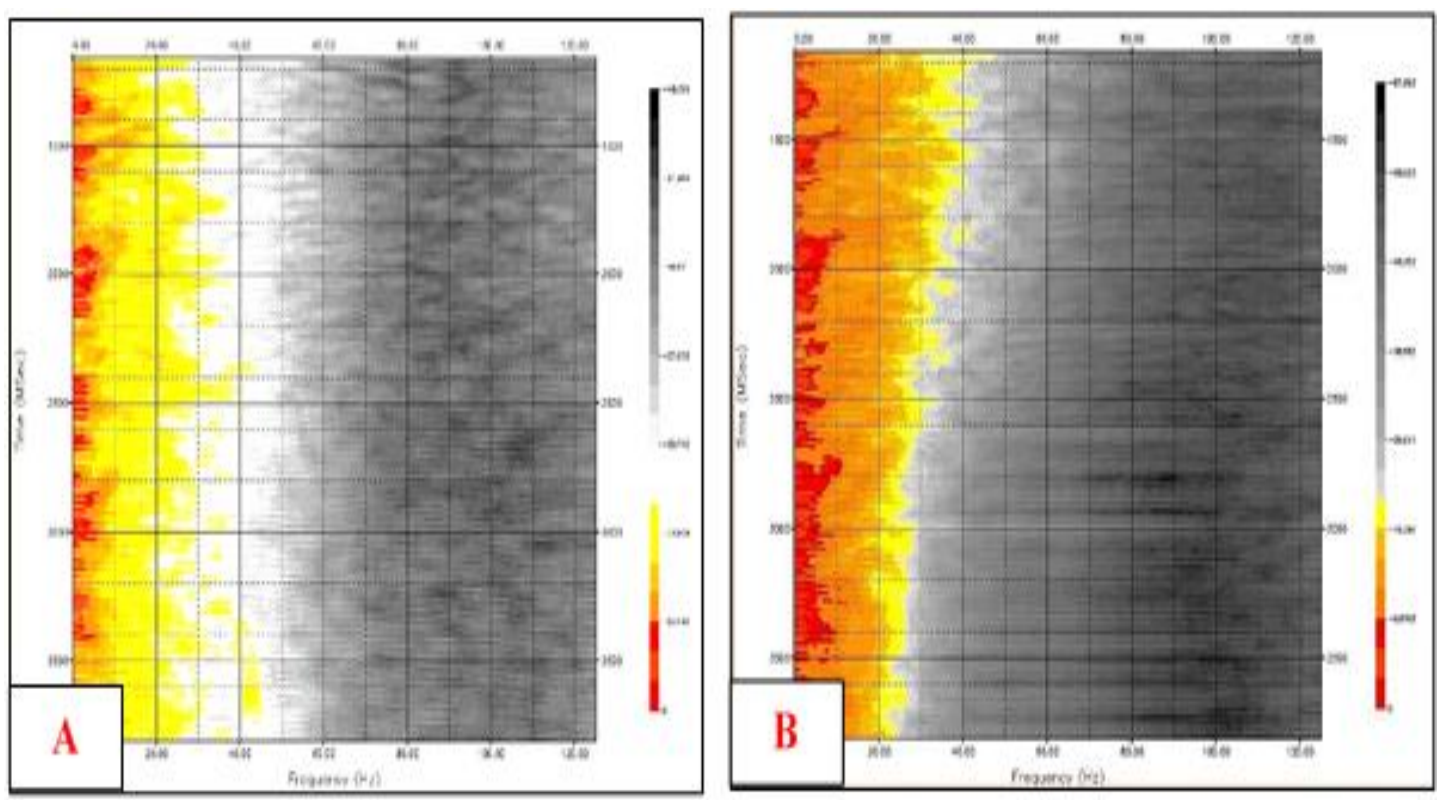

Figure 7- The Time-Frequency distribution of BS-92 seismic line; (A) Final with residual stacked seismic section. (B) Post-Stack Time Migration seismic section.
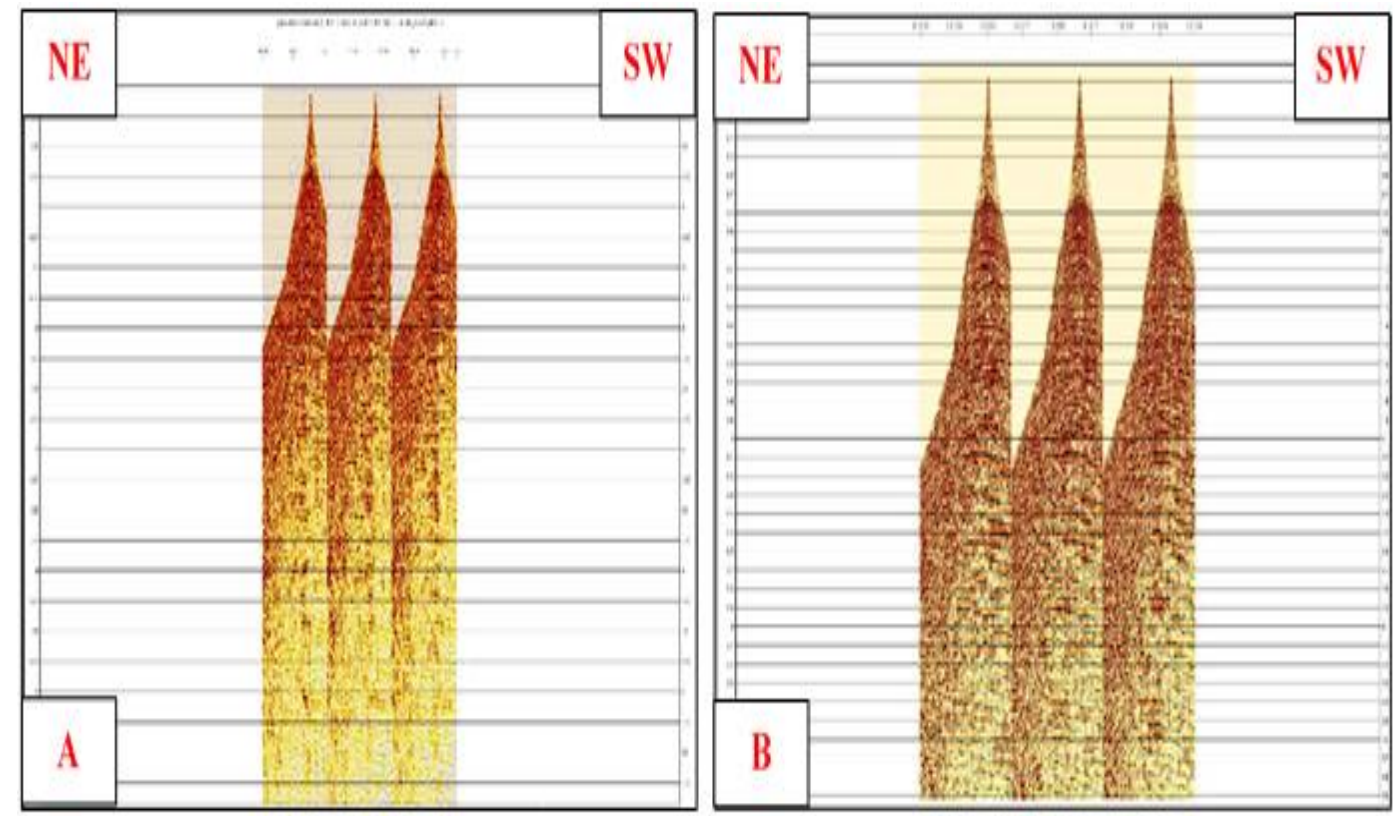

Figure 8- Offset classes of BS-92 line; (A) Non-processed raw offset classes. (B) Final with residual shot-points. 
The ISO-velocity spectrum shows a strong smoothing in the offset classes before applying the stacking stage (Figure-9). Finally, the stacking process could be applied on these seismic data to compare them with the other stacked sections to achieve better subsurface image (Figure-10)
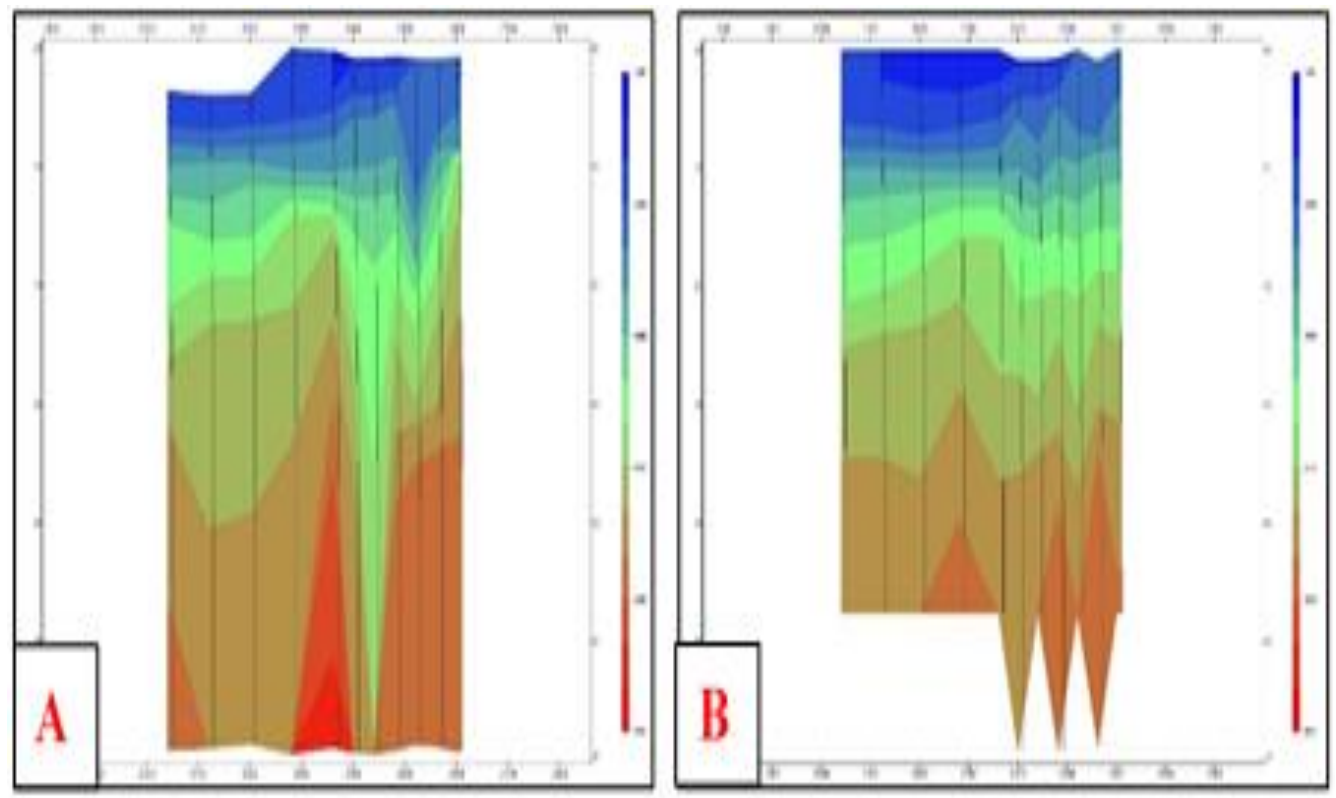

Figure 9- The ISO velocity distribution of BS-92 seismic line; (A) Final with residual stacked. (B) Pre-Stack Time Migration.

For the QC of the migration process, the Time-Frequency distribution slice (Figure-11) illustrates a clear difference between the results of Post-STM (Figure-11A) and Pre-STM (Figure-11B). Comparison of Pre-STM and Post-STM seismic sections in Time-Frequency domain shows improvement of the signal in the Pre-migrated seismic section.
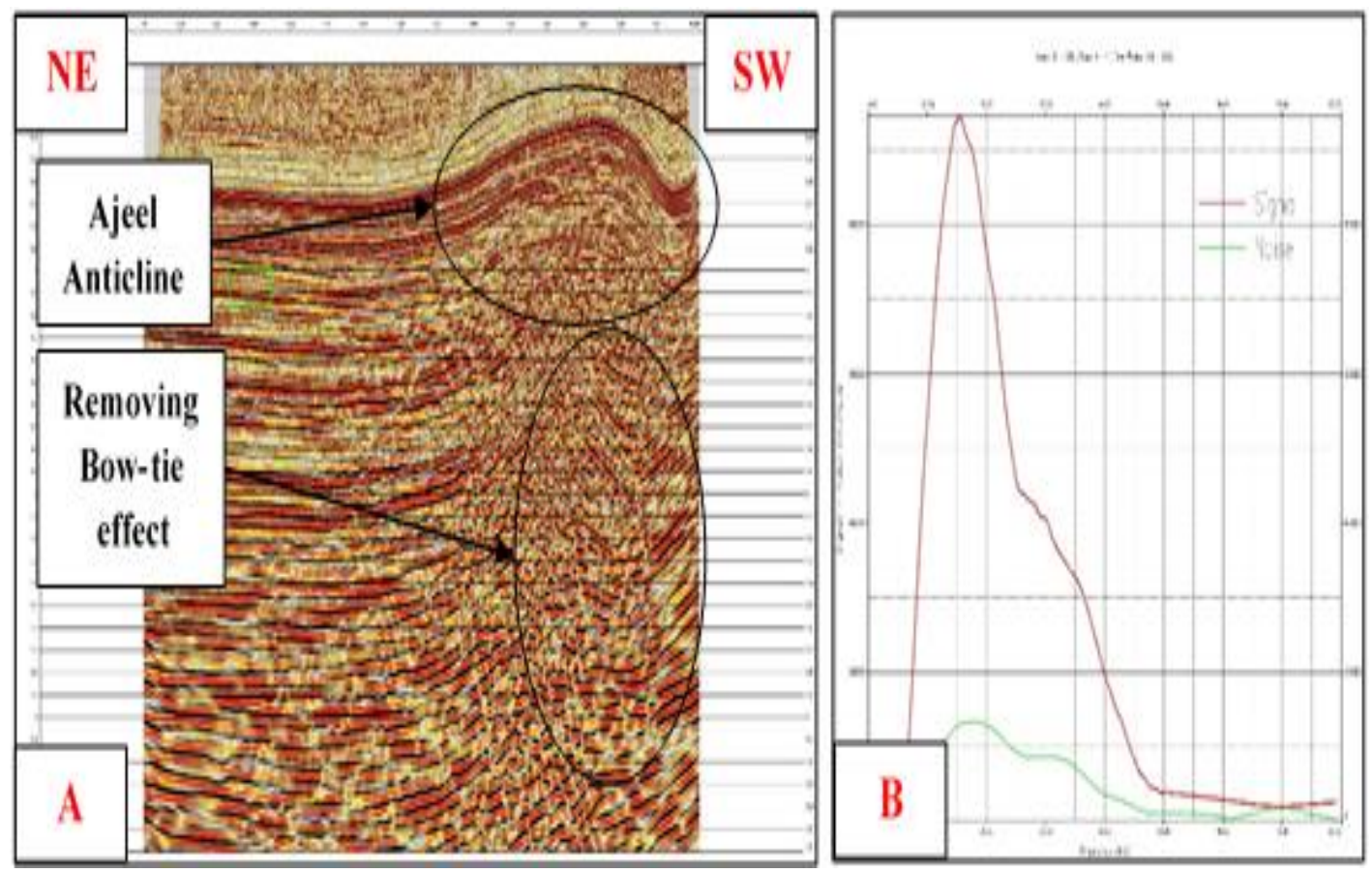

Figure 10- (A) Pre-Stack Time Migration seismic section of BS-92 seismic line showing Ajeel anticline and "Bow-tie" effect. (B) Signal to Noise ratio amplitude. 
Dip- Dependent Median Filter (DDMED) was used as a QC of the migration process; it is clear that the Pre-STM image (Figure-12A) is improved as compared to that of the Post-STM (Figure-12B).
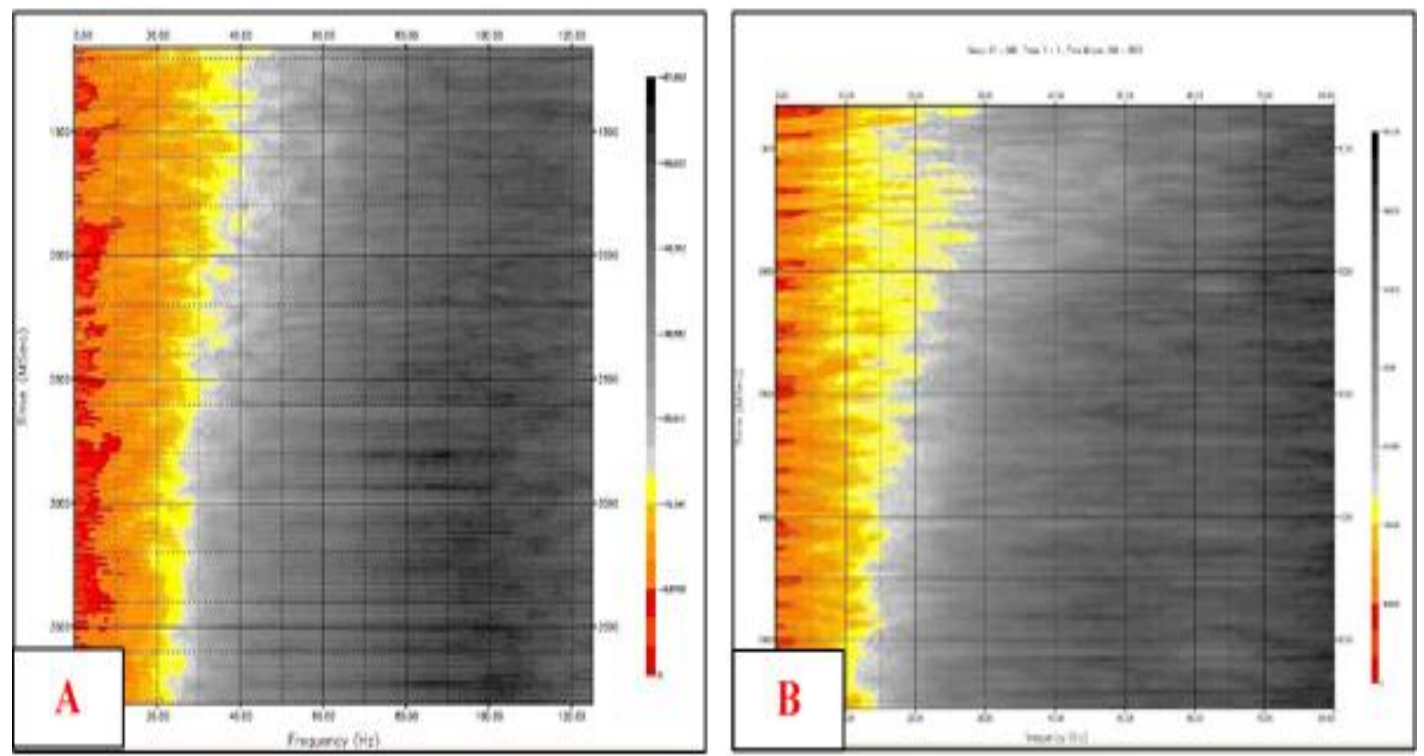

Figure 11- The Time-Frequency distribution of BS-92 seismic line; (A) Post-Stack Time Migration seismic section. (B) Pre-Stack Time Migration seismic section.
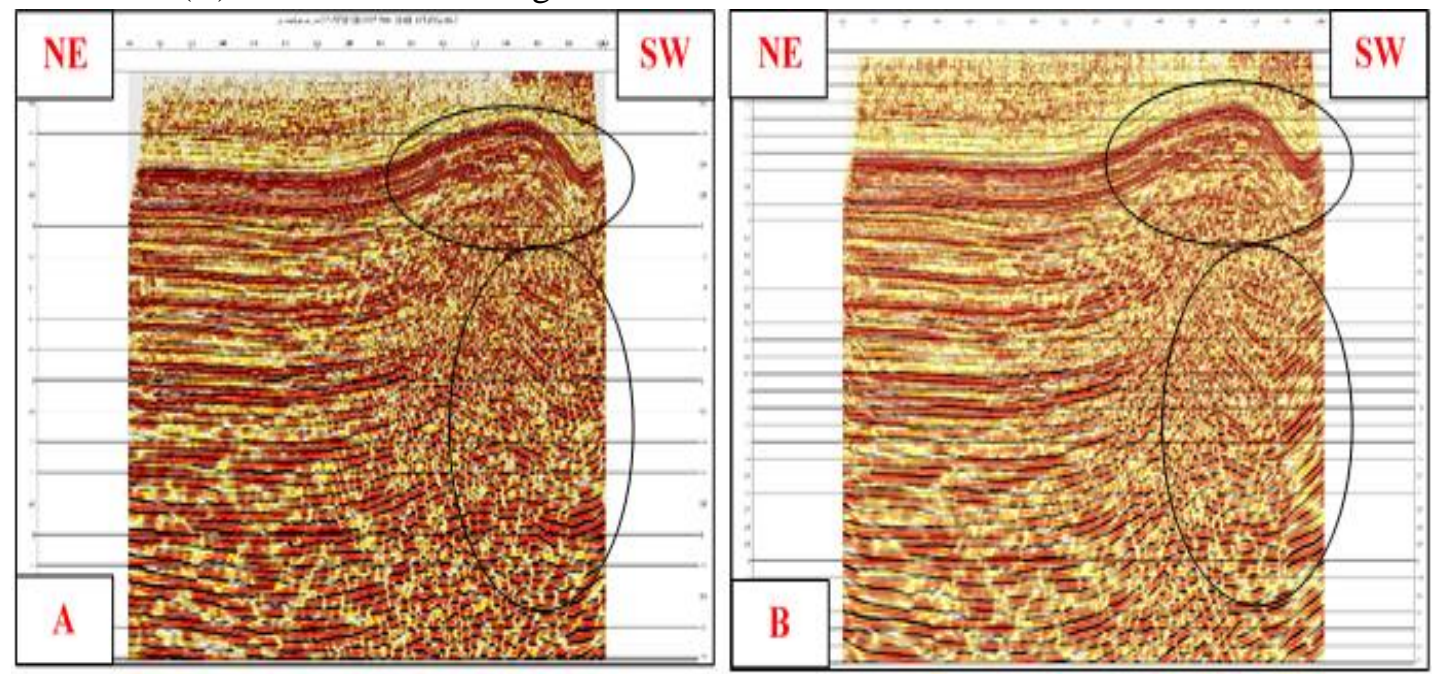

Figure 12- Stacked seismic section of BS-92 seismic line; (A) Pre-Stack Time Migration with dipremoval filter. (B) Post-Stack Time Migration with dip-removal filter.

\section{Discussion}

This research is concerned with applying 2D seismic migration before and after common-midpoint stack. We described a practical method with the Kirchhoff formula of migration. The migration process largely depends on velocity because the correct position of the common-depth point is very important in earth modeling. As a first step, data were subjected to a complete processing sequence with the application of residual static correction, except for the migration step. Then, the Post-Stack Time Migration was applied. Velocity is one of the significant parameters of migration. Velocity of migrated gathers is more accurate than that of unmigrated gathers (Figure-9), thus it must be re-picked when the Pre-STM stage is applied.

The imaging problem is complicated and related directly with the subsurface structures and the field parameters that are used for recording the seismic data. Subsurface structures in the seismic method are classified according to their degree of complicity and velocity. The migration technique can be applied in two stages (Post and Pre-STM), providing the same subsurface image when it is applied on subsurface structures, without dipping and variations in lateral velocity. The migration 
technique cannot be useful, in both types, when the degree of structures complexity is high by means of higher dips and robust variations in lateral velocity; the Pre-STM image is improved more than that of Post-STM.

The Post-STM method is faster than Pre-STM in image processing, but it might result in lower lateral resolution. One needs to be concerned with many characteristics in the geometry of the field survey, such as the length of the seismic line which must be suitable to consent steeply dipping subsurface structures to migrate to their precise subsurface setting.

\section{Conclusions}

Kirchhoff method of time migration was applied in Pre-and Post-Stack time migration of the BS92 survey line. The results showed good-quality and accurate images for the subsurface Ajeel anticline along with improved signal to noise ratio. This study made a comparison between the Post-STM and Pre-STM approaches. The Pre-STM provided higher quality of subsurface image than that of the PostSTM. This difference is probably due to variations in subsurface structural complicity, since Ajeel anticline has a dipping value of lower than $65^{\circ}$, and lateral velocity.

The processing resulted in demonstrating the inter layer geology (thin layers) between the essential layers, due to the effects of velocity analysis. In addition, we can conclude that the velocity on the migrated gather was more accurate than that of the unmigrated gather, which can be attribute to the velocity treats with CMP in the true position. The Time-Frequency slice and velocity analyses confirmed that the Pre-STM is more efficient than the Post-STM. The Bow-Tie syncline that appeared on the zero-offset seismic section (Figure-4) moved towards the up-dips and turned into syncline on the migrated section (Figures- 10 and 11). Another reason to form the Bow-Tie effects in the stacked section is the velocity errors in the Kirchhoff migration method, which is produced by the usage of velocities lower than those considered to be medium.

\section{References}

1. Yilmaz, O. 2001. Seismic data analysis: Processing, inversion, and interpretation of seismic data. Society of exploration geophysicists. pp. 502-520.

2. Gardner, G. H. 1985. Migration of seismic data (No. 4). Society of Exploration Geophysicists. 462pp. https://agupubs.onlinelibrary.wiley.com/doi/abs/10.1029/89EO00070

3. Schleicher, J., Hubral, P., Tygel, M. and Jaya, M. S. 1997. Minimum apertures and Fresnel zones in migration and demigration. Geophysics, 62(1): 183-194.

4. Bancroft, J. C. 2007. A Practical Understanding of Pre-and Poststack Migrations: Volume 2 (Prestack) Volume 2 (Prestack). Society of Exploration Geophysicists. Chapter 8, pp. 8-58.

5. Loewenthal, D., Lu, L., Roberson, R. and Sherwood, J. 1976. The wave equation applied to migration. Geophysical Prospecting, 24(2): 380-399.

6. Li, X. and Bancroft, J. C. 1998. The natural relation between prestack time migration and residual statics analysis. CREWES Project Research Report. 10: 1-38.

7. Claerbout, J. F. 1985. Imaging the earth's interior (Vol. 1). Oxford: Blackwell scientific publications. $274 \mathrm{pp}$.

8. Al-Ameri, T. K., Al-Jubouri, N. M., Isa, M. J. and Al-Azzawi, R. E. 2013. Hydrocarbons generation potential of the Jurassic-Lower Cretaceous Formation, Ajeel field, Iraq. Arabian Journal of Geosciences, 6(10): 3725-3735.

9. Kammouna, J. R. 2013. Seismic-Stratigraphy Study for Ajeel-Kirkuk Anticline of Tertiary Period. Internal Report of Iraqi Oil Exploration Company, (624): 1-56. (In Arabic).

10. Jassim, S. Z. and Goff, J. C. 2006. Geology of Iraq. DOLIN, distributed by Geological Society of London. pp. 73-76.

11. Aqrawi, A. A., Goff, J. C., Horbury, A. D. and Sadooni, F. N. 2010. The petroleum geology of Iraq. Scientific Press. pp. 518-526.

12. Obaid, F. A. and Al-Rahim, A. M. 2019. Pre and Post-Stack Imaging of 2D Seismic Data Using Time Migration for Ajeel Oil field, Central of Iraq. Iraqi Journal of Science, 60(10): 2186-2195.

13. Kopal, L., Č́žžek, P. and Milička, J. 2016. Geological model of Lobodice underground gas storage facility based on 3D seismic interpretation. Contributions to Geophysics and Geodesy, 46(2): 125-135.

14. Dobrin, M. B. and Savit, C. H. 1988. Introduction to geophysical prospecting (Vol. 4). New York: McGraw-hill, 271-273. 